\title{
Active-Phase Formation and Stability of Gd/Pt(111) Electrocatalysts for Oxygen Reduction: An In Situ Grazing Incidence X-Ray Diffraction Study
}

Escribano, Maria Escudero; Pedersen, Anders Filsøe; Ulrikkeholm, Elisabeth Therese; Jensen, Kim Degn; Hansen, Martin H.; Rossmeisl, Jan; Stephens, Ifan E. L.; Chorkendorff, Ib

Published in:

Chemistry - A European Journal

Link to article, DOI:

10.1002/chem.201801587

Publication date:

2018

Document Version

Peer reviewed version

Link back to DTU Orbit

Citation (APA):

Escribano, M. E., Pedersen, A. F., Ulrikkeholm, E. T., Jensen, K. D., Hansen, M. H., Rossmeisl, J., Stephens, I. E. L., \& Chorkendorff, I. (2018). Active-Phase Formation and Stability of Gd/Pt(111) Electrocatalysts for Oxygen Reduction: An In Situ Grazing Incidence X-Ray Diffraction Study. Chemistry - A European Journal, 24(47), 12280-12290. https://doi.org/10.1002/chem.201801587

\section{General rights}

Copyright and moral rights for the publications made accessible in the public portal are retained by the authors and/or other copyright owners and it is a condition of accessing publications that users recognise and abide by the legal requirements associated with these rights.

- Users may download and print one copy of any publication from the public portal for the purpose of private study or research.

- You may not further distribute the material or use it for any profit-making activity or commercial gain

- You may freely distribute the URL identifying the publication in the public portal 


\section{Active-Phase Formation and Stability of Gd/Pt(111) Electrocatalysts for Oxygen Reduction: An In Situ Grazing Incidence X-Ray Diffraction Study}

María Escudero-Escribano ${ }^{+},{ }^{[a, b, c]}$ Anders F. Pedersen ${ }^{+[b]}$ Elisabeth T. Ulrikkeholm, ${ }^{[b]}$ Kim D. Jensen, ${ }^{[a, b]}$ Martin H. Hansen, ${ }^{[c]}$ Jan Rossmeisl, ${ }^{[a]}$ Ifan E. L. Stephens, ${ }^{[b, d]}$ and Ib Chorkendorff*[b]

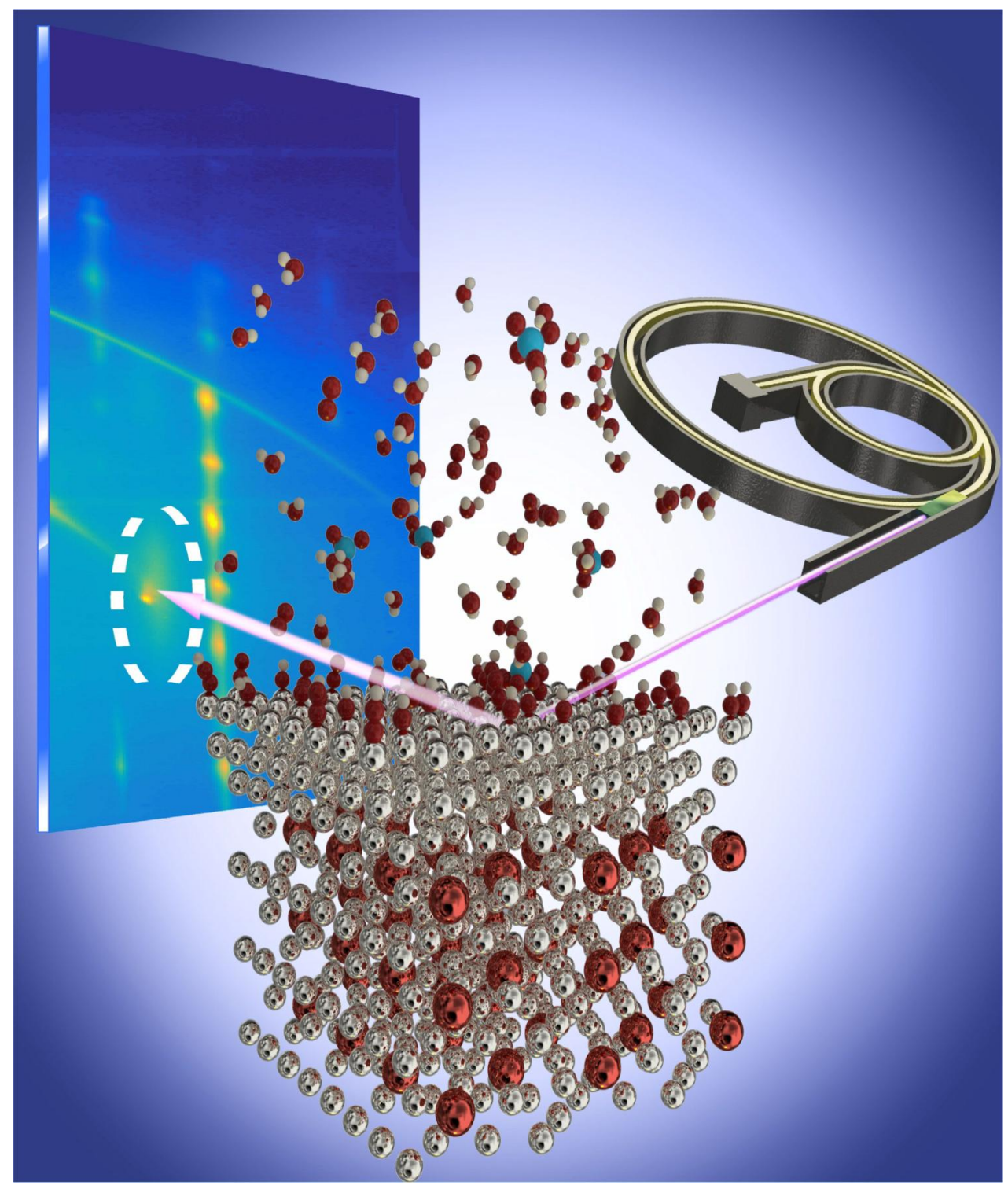


Abstract: Alloys of platinum and gadolinium present significant activity enhancement over pure Pt for the oxygen reduction reaction (ORR), both in the form of extended electrode surfaces and nanoparticulate catalysts. The active phase consists of a compressed Pt overlayer formed on $\mathrm{Pt}_{5} \mathrm{Gd}$ electrodes upon exposure to the electrolyte by acid leaching. Here, we investigate the formation, strain and correlation lengths of the active $\mathrm{Pt}$ overlayer by using in situ synchrotron grazing incidence X-ray diffraction on $\mathrm{Gd}$ /

\section{Introduction}

Electrochemical energy conversion and storage technologies are essential for the development of a sustainable economy. ${ }^{[1-3]}$ Proton exchange membrane fuel cells (PEMFCs), which convert the chemical energy stored in hydrogen bonds directly into clean electricity, are expected to play a key role in future renewable energy schemes. ${ }^{[4]}$ However, the slow kinetics of the oxygen reduction reaction [ORR, see Eq. (1)] at the cathode limits the performance of PEMFCs. Under PEMFC conditions, only Pt-based electrocatalysts present both high activity and stability for the ORR. ${ }^{[4-7]}$ State-of-the-art PEMFCs require a high Pt loading of $0.25 \mathrm{~g} \mathrm{~kW}^{-1}$, of which $0.2 \mathrm{mg} \mathrm{cm}^{-2}$ are needed to catalyse the ORR at the cathode: ${ }^{[5,8]}$

$\mathrm{O}_{2}+4 \mathrm{H}^{+}+4 \mathrm{e}^{-} \rightarrow 2 \mathrm{H}_{2} \mathrm{O}$

To design and develop more efficient electrocatalysts for the ORR while reducing the $\mathrm{Pt}$ loading at the cathode, it is crucial to elucidate the factors controlling this reaction. ${ }^{[6,9,10]}$ A Sabatier volcano relation exists between the ORR activity and the binding energy of the reaction intermediates $\mathrm{CO}, \mathrm{OH}$ and $\mathrm{OOH}),{ }^{[11-13]}$ in which the apex of the volcano corresponds to a

[a] Prof. M. Escudero-Escribano, ${ }^{+}$Dr. K. D. Jensen, Prof. J. Rossmeisl Department of Chemistry, Nano-Science Center, University of Copenhagen Universitetsparken 5, 2100 Copenhagen $\varnothing$ (Denmark)

E-mail:maria.escudero@chem.ku.dk

[b] Prof. M. Escudero-Escribano, ${ }^{+}$Dr. A. F. Pedersen, ${ }^{+}$Dr. E. T. Ulrikkeholm, Dr. K. D. Jensen, Dr. I. E. L. Stephens, Prof. I. Chorkendorff Department of Physics, Surface Physics and Catalysis Technical University of Denmark Fysikvej, Building 312, 2800 Kgs. Lyngby (Denmark) E-mail: ibchork@fysik.dtu.dk

[c] Prof. M. Escudero-Escribano, ${ }^{+}$Dr. M. H. Hansen Department of Chemical Engineering SUNCAT Center for Interface Science and Catalysis Stanford University, 443 Via Ortega, Stanford, California 94305 (USA)

[d] Dr. I. E. L. Stephens

Department of Materials, Imperial College London

2.03b, Royal School of Mines, Prince Consort Rd

London SW7 2AZ England (UK)

$\left.{ }^{[+}\right]$These authors contributed equally to this work.
Pt(111) single-crystalline electrodes. The overlayer forms upon exposure to electrolyte under open circuit conditions; the compressive strain relaxes slightly upon repeated electrochemical cycling in the potential range 0.6 to $1.0 \mathrm{~V}$ versus the reversible hydrogen electrode (RHE). In addition, the strain relaxes strongly when exposing the electrode to $1.2 \mathrm{~V}$ versus RHE, and the thickness of the crystalline portion of the overlayer increases with potential above $1.3 \mathrm{~V}$ versus RHE.

weakening of the $\mathrm{OH}$ binding energy of $\sim 0.1 \mathrm{eV}$ as compared to pure $\mathrm{Pt}^{\left[{ }^{11]}\right.}$ On Pt-alloys, the $\mathrm{OH}$ binding energy can be weakened by means of electronic effects such as ligand ${ }^{[14]}$ and/ or strain effects. ${ }^{[15,16]}$ Although ligand effects originate from subsurface alloying, ${ }^{[17,18]}$ strain effects occur when a laterally compressed/expanded Pt overlayer is formed. ${ }^{[15,19]}$

Alloys of Pt and late transition metals such as $\mathrm{Ni}, \mathrm{Co}, \mathrm{Fe}$ and $\mathrm{Cu}$ have been intensively studied as ORR electrocatalysts during the last two decades. ${ }^{[6,7,15,20-23]}$ These alloys form a Pt overlayer after immersion in acidic electrolyte because late transition metals are unstable towards dissolution in acidic media. ${ }^{[24]}$ The pioneer model studies on $\mathrm{Pt}_{3} \mathrm{Ni}(h k l)$ single-crystal alloys by Markovic and co-workers showed that the active site corresponded to the closely packed (111) surface. ${ }^{[21]}$ In situ surface X-ray diffraction (XRD) measurements revealed the formation of a $\mathrm{Pt}(111)$ overlayer with $\mathrm{Ni}$ present in the sub-surface atomic layer. ${ }^{[25]}$ On the other hand, in situ scanning tunnelling microscopy (STM) measurements on Pt-Fe alloys revealed the formation of $\mathrm{Pt}$ (111)-like surfaces after acid leaching. Although Pt-late transition metal alloys present a significant activity enhancement over pure $\mathrm{Pt}$, they typically degrade by dealloying under fuel cell reaction conditions. ${ }^{[5,26]}$ Nonetheless, some novel concepts of nanocatalysts such as Pt-based nanowires ${ }^{[27]}$ and nanoframes ${ }^{[28]}$ achieve outstanding activity and high stability during short-term accelerated stability tests. Nevertheless, for novel catalysts, it has been challenging to achieve the full enhancement exhibited in rotating disk electrode (RDE) measurements, when tested in fuel cells. ${ }^{[5,29,30]}$

We have recently demonstrated that alloys of $\mathrm{Pt}$ and rare earth/alkaline earth metals display a remarkable activity enhancement over pure $\mathrm{Pt}^{[31-34]}$ Polycrystalline Pt-lanthanide alloys such as $\mathrm{Pt}_{5} \mathrm{Gd}$ and $\mathrm{Pt}_{5} \mathrm{~Tb}$ are within the most active polycrystalline electrodes for the ORR, presenting up to a 6-fold improvement of activity over polycrystalline $\mathrm{Pt}{ }^{[33]}$ In contrast to Pt-late transition metal alloys, Pt-lanthanide alloys have a very negative enthalpy of formation. ${ }^{[35]}$ This may stabilise them against dealloying ${ }^{[36]}$ because the alloying energy is related to the diffusion barriers of the minority component of the alloy. ${ }^{[37]}$ XRD measurements revealed that polycrystalline $\mathrm{Pt}_{5} \mathrm{M}$ alloys presented a hexagonal $\mathrm{Cu}_{5}$ Ca-type bulk structure. ${ }^{[33]}$ The active surface phase of Pt-lanthanide alloys consists of a 3-5 atom thick Pt overlayer formed by acid leaching ${ }^{[33]}$ because lanthanides are thermodynamically unstable towards dissolution in the acidic electrolyte. ${ }^{[32]}$ Thus, the kinetic stability of these 
alloys is reliant on the structure and properties of the Pt overlayer, and its ability to protect the bulk alloys from further dealloying. ${ }^{[33]}$ Our density functional theory (DFT) calculations suggested that the thick Pt overlayer would correspond to a closely packed Pt overlayer under compressive strain. ${ }^{[32]}$ More recently, we investigated $\mathrm{Pt}_{x} \mathrm{Y}$ and $\mathrm{Pt}_{x} \mathrm{Gd}$ nanoparticulate catalysts of these alloys. ${ }^{[38-40]}$ Extended X-ray absorption fine structure (EXAFS) measurements showed that mass-selected $\mathrm{Pt}_{X} \mathrm{Y}$ and $\mathrm{Pt}_{x} \mathrm{Gd}$ nanoparticles were under compressive strain, even after carrying out ORR measurements. Furthermore, their specific activity exhibited an exponential dependence with the compressive strain $;{ }^{[38]}$ this result is in agreement with the formation of a compressed Pt shell, which would cause the weakening of the $\mathrm{OH}$ binding energy. ${ }^{[11]}$

To study the structure of the Pt overlayer, we recently prepared and investigated well-defined $\mathrm{Y} / \mathrm{Pt}(111)$ and $\mathrm{Gd} / \mathrm{Pt}(111)$ single-crystalline surfaces by depositing thick layers of $Y$ or $\mathrm{Gd}$ on $\mathrm{Pt}(111)$ substrates in ultra-high vacuum (UHV) creating bulklike structures. ${ }^{[41-43]}$ XRD measurements showed that Gd/Pt(111) presented similar $\mathrm{Cu}_{5} \mathrm{Ca}$-type hexagonal structure to that observed by polycrystalline alloys. ${ }^{[32,33,42,43]}$ The alloy film on top of $\mathrm{Pt}(111)$ either followed the (111) orientation or it was rotated by $30^{\circ} .^{[42,43]}$ After electrochemistry, a thick Pt overlayer of about $1 \mathrm{~nm}$ thickness was formed onto the $\mathrm{Gd} / \mathrm{Pt}(111)$ electrode by acid leaching, similarly to that formed on polycrystalline and nanoparticulate alloys. Ex situ grazing incidence X-ray diffraction (GI-XRD) measurements revealed the formation of a crystalline Pt overlayer under compressive strain after electrochemical experiments in acidic electrolyte. ${ }^{[43]}$ However, it remains an open question what the structure is in situ, and how it evolves as a function of potential.

Elucidating the active surface phase in situ and understanding its degradation mechanisms ${ }^{[44,45]}$ is essential to optimise the electrocatalytic efficiency and durability at the cathode of low-temperature fuel cells. ${ }^{[5]}$ In situ synchrotron studies such as GI-XRD on model electrode surfaces are key to understand the structure-activity-stability relationships in electrocatalysis. ${ }^{[44,46,47]}$ Here, we aim to shed light on the formation of the Pt overlayer on Gd/Pt(111) single-crystalline electrodes and correlate the overlayer strain with the electrochemical treatments. For this purpose, we used the in situ XRD setup sketched in Figure 1 at Stanford Synchrotron Radiation Lightsource (SSRL). These measurements allowed us to investigate the pre-prepared $\mathrm{Gd} / \mathrm{Pt}(111)$ samples through in situ GI-XRD while the samples were maintained in a hanging meniscus three-electrode configuration. This electrochemical cell allowed cyclic voltammetry measurements to be carried out in parallel with Gl-XRD measurements. The grazing incidence geometry provides an increased surface sensitivity, and combining a $2 \mathrm{D}$ pixel detector and sample rotation around the surface normal $(\varphi)$ allows a large part of reciprocal space to be mapped. The aqueous electrolyte is transparent for the hard X-rays, allowing us to track the position and shape of the diffraction peaks associated with the Pt overlayer during in situ electrochemical operation. In addition to the in situ GI-XRD measurements, we further study the ORR activity and stability of $\mathrm{Gd} / \mathrm{Pt}(111)$ by means of cyclic voltammetry. Our experimental results on the

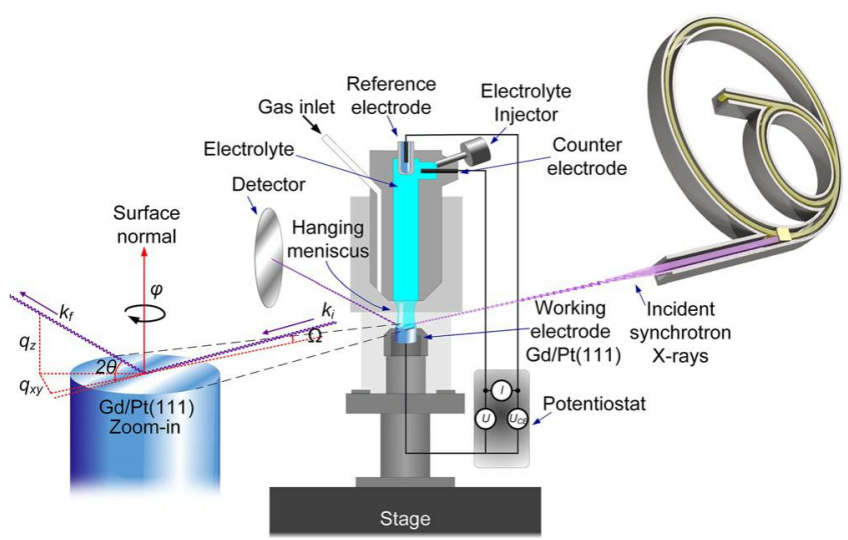

Figure 1. Schematic representation of the in situ X-ray diffraction setup and three-electrode electrochemical cell for characterisation of $\mathrm{Gd} / \mathrm{Pt}(111)$ singlecrystal electrodes in the hanging meniscus configuration used at SSRL. This setup enabled the evaluation of the Pt overlayer formation and evolution in situ, during the electrochemical experiments on $\mathrm{Gd} / \mathrm{Pt}(111)$ surfaces.

overlayer structure are rationalised by means of DFT calculations.

In particular, we aim to address the following questions: (i) which conditions are needed to form the active surface phase, that is, the compressed Pt overlayer on Gd/Pt(111) in acidic electrolyte; (ii) how stable the Pt overlayer is and how its structure evolves after prolonged cycling under fuel-cell relevant potentials ( 0.6 to $1.0 \mathrm{~V}$ vs. the reversible hydrogen electrode, RHE); and (iii) what are the degradation mechanisms of the Pt overlayer after cycling to very oxidising potentials (up to $1.6 \mathrm{~V}$ vs. RHE). The unique combination of in situ structural and electrochemical measurements with theoretical calculations provide us with a detailed picture of the formation and evolution of the active surface phase for the electrocatalytic oxygen reduction reaction.

\section{Results and Discussion}

Prior to the in situ X-ray diffraction measurements, we prepared two Gd/Pt(111) single-crystalline surfaces under UHV

Mara Escudero-Escribano obtained her PhD in Chemistry from the Autonomous University of Madrid in 2011. She carried out postdoctoral research stays at the Technical University of Denmark and Stanford University. Since March 2017, she is Assistant Professor at the Department of Chemistry at the University of Copenhagen, where she leads the Nanoelectrocatalysis Group. Maria's research has been recognised by numerous prestigious awards, including the European Young Chemist Award 2016 (Gold Medal, 35 years level), the Electrochemical Society Energy Technology Division Young Investigator Award 2018, a Villum

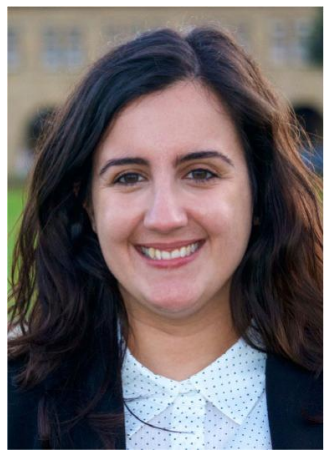

Young Investigator Grant 2018, and the Princess of Girona Foundation Scientific Research Award 2018. 
(see the Experimental Section). A full description of the preparation of $\mathrm{Gd} / \mathrm{Pt}(111)$ was described elsewhere. ${ }^{[42]}$ The alloy phase on one of the two crystals was rotated $30^{\circ}$ as compared to the $\mathrm{Pt}(111)$ substrate, whereas it was not rotated on the other. We had observed both the rotated and non-rotated phases of the bulk alloy in our previous studies on $\mathrm{Gd}$ / $\mathrm{Pt}(111) \cdot{ }^{[42,43]}$ To distinguish the alloy phase rotation of the two crystals, we labelled them as $R 30$ (rotated $30^{\circ}$ ) and $R 0$ (non-rotated), respectively. It must be noted that these rotation angles are also relevant for the $\mathrm{Pt}$ overlayer structure because the overlayer will follow the rotation of the alloy phase. ${ }^{[43]}$

The two Gd/Pt(111) single crystals were subjected to two different electrochemical treatments. We carried out the first treatment on the $\mathrm{Gd} / \mathrm{Pt}(111) R 0$ sample, consisting of an 8000cycle stability test in the range from 0.6 to $1.0 \mathrm{~V}$ versus the reversible hydrogen electrode (RHE). The second treatment, on the $\mathrm{Gd} / \mathrm{Pt}(111) R 30$ consisted of cycling the potential between $0 \mathrm{~V}$ to a maximum potential $\left(U_{\max }\right)$ vs. RHE, $U_{\max }$ potential sequentially increasing up to $1.6 \mathrm{~V}$ vs. RHE.

To gain a deeper understanding on the formation of the active Pt overlayer, we examined both the position and shape of the diffraction peaks from the compressed overlayer during the electrochemical treatments. The $\mathrm{Gd} / \mathrm{Pt}(111)$ alloy phase gives rise to a complex stacking sequence of hexagonal layers, ${ }^{[42]}$ thus generating a rich diffraction pattern. The $\mathrm{Pt}(111)$ substrate exhibits fewer diffraction peaks due to the small unit cell. However, these peaks are very intense because the sample is a large $\mathrm{Pt}(111)$ single crystal. Furthermore, "powderring"-like diffraction features were observed. Considering that the radii of the latter match that of $\mathrm{Pt}$, we hypothesise that these features come from randomly oriented Pt grains on the edges of the crystal.

Figure 2 shows a representative diffraction pattern from $\mathrm{Gd}$ / $\mathrm{Pt}(111) R 0$ exhibiting these features (Figure $2 \mathrm{a}$ ) as well as $\mathrm{Gd}$ / $\mathrm{Pt}(111) R 30$ (Figure $2 \mathrm{~b}$ ). The image of Figure 2 has been corrected and shows the intensity as a function of in-plane $\left(Q_{x y}\right)$ and out-of-plane $\left(Q_{z}\right)$ components of the scattering vector, $Q$. The overlayer diffraction peak is shown inside the white dashed ellipse. These results show that the overlayer is very thin because the diffraction peak is highly elongated in the $z$-direction. Due to the alloy phase and overlayer not being rotated on the $\mathrm{Gd} / \mathrm{Pt}(111) R 0$ sample, ${ }^{[43]}$ the $\mathrm{Pt}(111)$ substrate $(1,0,1)$ diffraction spot is seen inside the red dotted circle next to the overlayer. These two peaks are not overlapping completely, showing that the overlayer is compressed relative to bulk $\mathrm{Pt}(111)$. On the $\mathrm{Gd} / \mathrm{Pt}(111) R 30$ sample there is a small spot corresponding to pure $\mathrm{Pt}(1,0,1)$, which is likely from a few misoriented grains; the intensity is much smaller compared to the $R 0$ sample. The two large arcs in the images most likely correspond to diffraction from randomly oriented Pt grains on the edge of the single crystal. The remaining diffraction is from the $\mathrm{Gd} / \mathrm{Pt}(111)$ alloy phase.

To quantify the changes taking place in both lattice parameter and correlation lengths of the overlayer, the diffraction peaks at different $\varphi$-angles were fitted by a two-dimensional pseudo-Voigt profile, that is, a combination of Gaussian and Lorentzian profiles. The position of the overlayer peaks relative

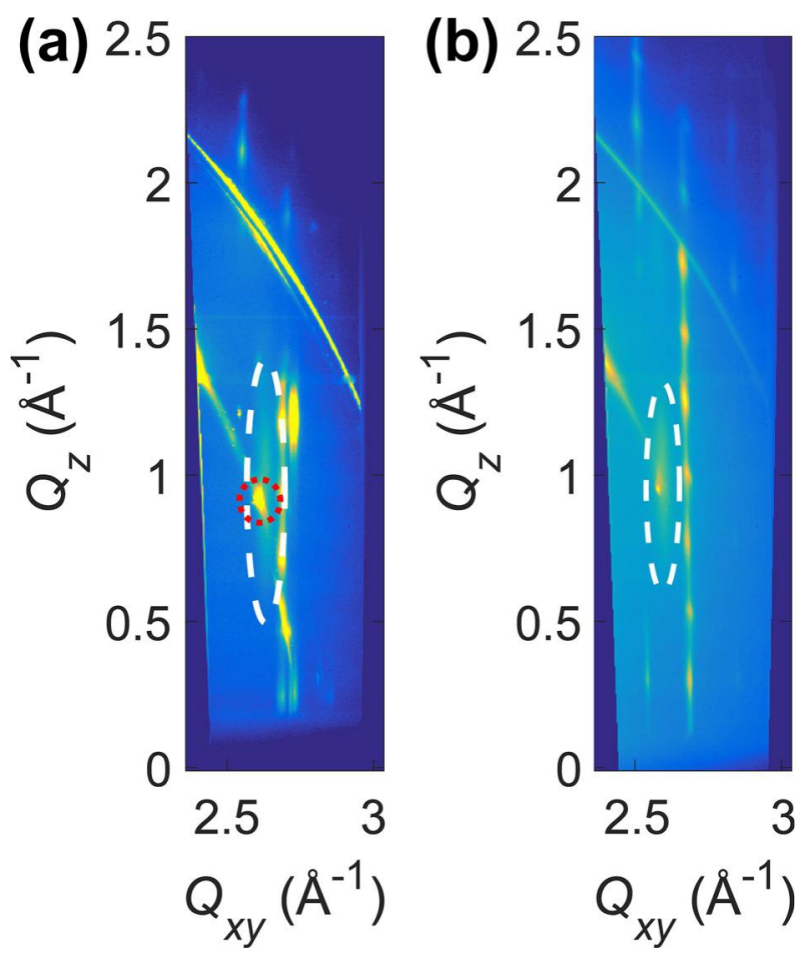

Figure 2. A representative diffraction image from the $\mathrm{Gd} / \mathrm{Pt}(111) R 0$ (a) and the $\mathrm{Gd} / \mathrm{Pt}(111) R 30$ samples (b), showing the intensity as a function of inplane $\left(Q_{x y}\right)$ and out-of-plane $\left(Q_{z}\right)$ components of the scattering vector, $Q$. The overlayer peak is seen in the white ellipse next to the $(1,0,1)$ diffraction peak from the $\mathrm{Pt}(111)$ substrate, indicating that the overlayer is not rotated from the substrate. The large arcs arise from randomly oriented Pt grains on the edge of the sample. The remaining features are from the $\mathrm{Gd} / \mathrm{Pt}(111)$ alloy phase.

to the $\mathrm{Pt}$ (111) substrate peaks were used to extract the relative strain of the overlayer, and the peak widths were used to estimate the correlation length. If we assume the entire overlayer is crystalline, the out-of-plane correlation length is the thickness of the overlayer.

Figure 3 shows the relative strain of the overlayer as a function of the electrochemical treatment for the $\mathrm{Gd} / \mathrm{Pt}(111) R 0$ sample, as compared to bulk Pt. Figure $3 \mathrm{a}, \mathrm{b}$ shows the inplane and out-of-plane strain evolution, respectively. Initially, the crystal was cycled from 0.0 to $0.6 \mathrm{~V}$ vs. RHE, and the diffraction pattern was recorded while keeping the potential fixed at $0.1,0.5$ and $0.6 \mathrm{~V}$ vs. RHE. This was followed by cycling from 0.0 to $0.8 \mathrm{~V}$ vs. RHE and XRD recording at $0.1,0.5$ and $0.8 \mathrm{~V}$ vs. RHE. The sample was finally cycled from 0.0 to $1.0 \mathrm{~V}$ vs. RHE with $\mathrm{XRD}$ recording at $0.1 \mathrm{~V}, 0.5 \mathrm{~V}$, and $1.0 \mathrm{~V}$ vs. RHE. All subsequent cycling was carried out from 0.6 to $1.0 \mathrm{~V}$ vs. RHE. This stability test was carried out at $100 \mathrm{mV} \mathrm{s}^{-1}$, and the cycling was either stopped to do XRD recording at $0.1,0.5$ and $0.9 \mathrm{~V}$ vs. $\mathrm{RHE}$, or the XRD recording was done during cycling. At this scan rate, a few cycles ran during $X$-ray exposure, and about 80 cycles passed during the entire XRD recording. The last data point was acquired after changing the electrolyte and exposing the electrode surface to air, followed by a few cycles from 0.0 to $1.0 \mathrm{~V}$ vs. RHE in the new electrolyte. The error bars represent the error in the peak position from fitting, and are representative of the strain changes seen in Figure 3. However, 

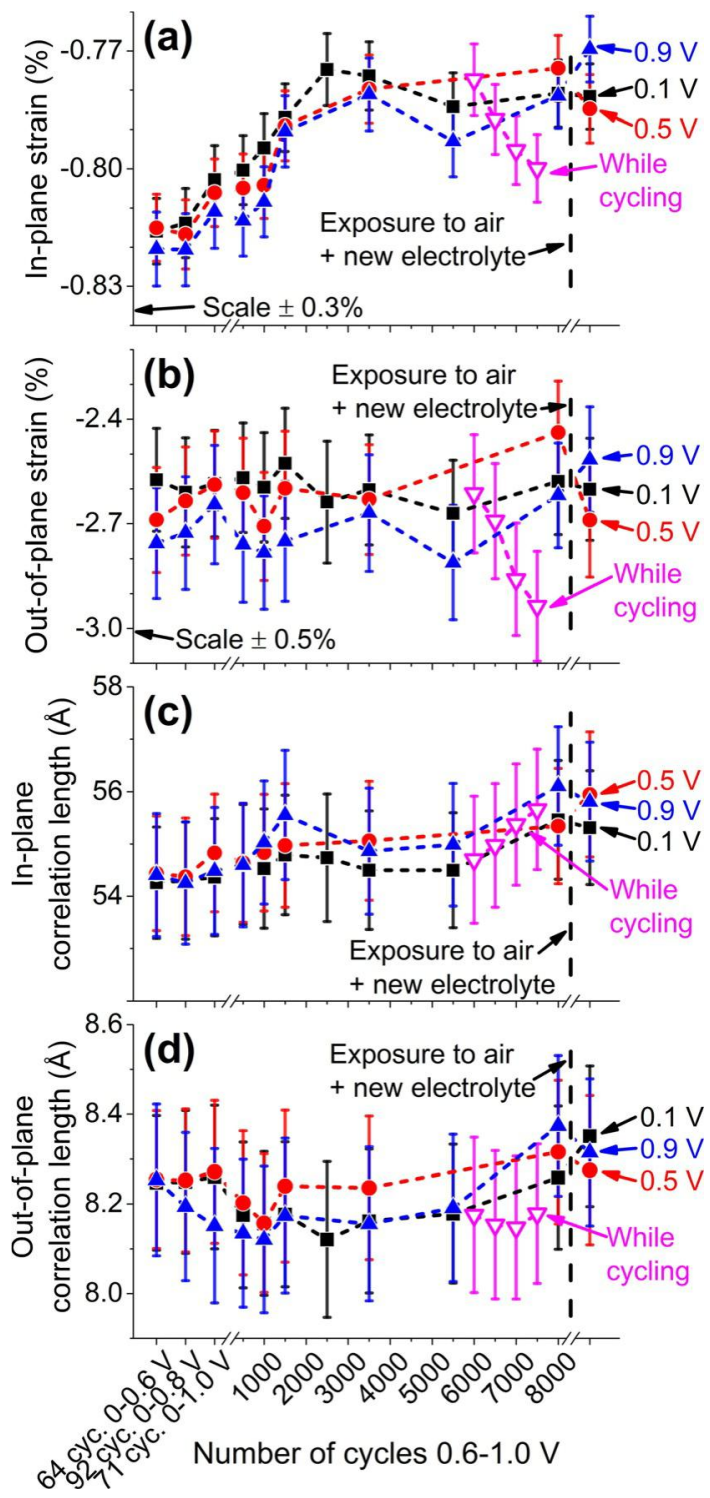

Figure 3. In-plane and out-of-plane components of the strain $(a, b)$ and correlation lengths $(c, d)$ of the overlayer relative to bulk Pt as a function of the electrochemical treatment on Gd/Pt(111)RO from in situ GI-XRD. The error bars represent the error in the overlayer peak position from the fitting. However, there is a global error in the strain value that comes from the combined uncertainty of the peak position of the overlayer and the Pt(111) substrate ( $\pm 0.3 \%$ for the in-plane strain and $\pm 0.5 \%$ for the out-of-plane strain). The correlation length has been calculated from the FWHM using Scherrer's equation. The error is from the fitting of the peak width of the pseudo-Voigt profile.

the combined error in the peak positions of the overlayer peaks and the substrate peaks gives a larger error for the strain that ideally should affect each measurement identically, and for the in-plane strain this error is $\pm 0.3 \%$ and for the outof-plane strain it is $\pm 0.5 \%$. Similar to the strain, we tracked the correlation length of the overlayer in situ as a function of the electrochemical treatment, as shown in Figure $3 c$, $d$ for the in-plane and out-of-plane correlation length, respectively. The correlation length was calculated from the full width at half maximum (FWHM) of the pseudo-Voigt profile, using Scherrer's formula with a shape factor of $K=0.886 .{ }^{[48]}$
According to Figure 3, the measured in-plane compressive strain after prolonged cycling between 0.0 and $1.0 \mathrm{~V}$ vs. RHE is about $0.8 \%$. The out-of-plane strain of the Pt overlayer is also compressive, which can be explained by the presence of Kagomé layer(s). ${ }^{[43]}$ During the cycling, the in-plane strain relaxes slightly, with most of the relaxation occurring in the first 2000 to 3000 cycles. After about 3000 cycles from 0.0 to $1.0 \mathrm{~V}$ vs. $R H E$, the structure of the overlayer seems very stable. Our earlier work on polycrystalline Pt-lanthanide alloys ${ }^{[33]}$ and mass-selected $\mathrm{Pt}_{x} \mathrm{Gd}$ nanoparticles ${ }^{[38]}$ suggests that the loss in electrocatalytic activity was due to strain relaxation, and most of the activity loss occurred with initial cycling.

Interestingly, the out-of-plane strain and crystallite sizes remain constant during the cycling procedure shown in Figure 3. At the end of the experiment, we replaced the electrolyte in the cell, exposing the $\mathrm{Gd} / \mathrm{Pt}(111) R 0$ single-crystalline electrode to air (as indicated in Figure 3), and the overlayer appeared to be very stable because its crystalline thickness remains constant for 8000 cycles, while maintaining the approximate $0.8 \%$ in-plane compression. This stable Pt overlayer under compressive strain had a thickness of about $8.3 \AA$ and persisted after 8000 cycles. Figure 4 shows a schematic illustration of the Pt overlayer ${ }^{[43]}$ and the in-plane and out-of-plane strain together with the in-plane and out-of-plane correlation lengths after 8000 cycles from 0.6 to $1.0 \mathrm{~V}$ vs. RHE in $0.1 \mathrm{M}$ $\mathrm{HClO}_{4}$ (see description of the electrochemical treatment above for the data presented in Figure 3).

The peak positions of the substrate, alloy and the overlayer revealed that they their $c$-axes were all tilted relative to the surface normal. Furthermore, the alloy and overlayer were both tilted more than the $\mathrm{Pt}(111)$ substrate, and all tilted in the same direction. The tilt angles are shown in Table 1. We must note that the surface tilt of the $\mathrm{Pt}(111)$ substrate on the $\mathrm{Gd} /$ $\mathrm{Pt}(111) R 0$ sample is believed to be a simple miscut of the crystal formed during the polishing procedure. The further tilt of the alloy thin film and overlayer relative to the $\mathrm{Pt}(111)$ substrate could be linked to strain accommodation. Considering that we did not observe this tilt on any other sample, we suspect that it might be related to the initial miscut of the $\mathrm{Pt}(111)$

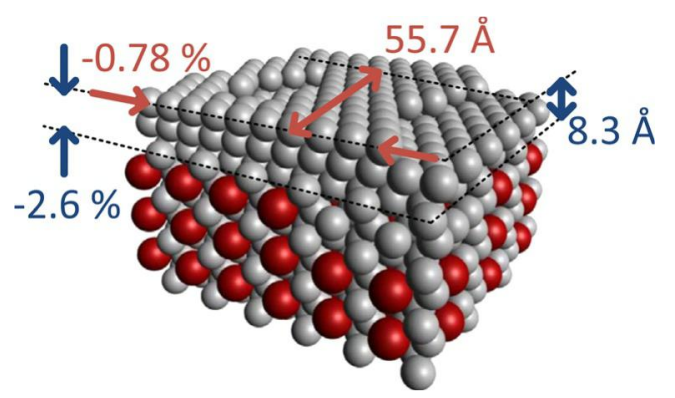

Figure 4. Schematic illustration of the $\mathrm{Gd} / \mathrm{Pt}(111) R 0$ sample including the $\mathrm{Pt}$ overlayer formed after the electrochemical treatment described in Figure 3. The in-plane (orange arrows) and out-of-plane (blue arrows) strain and correlation length values have been taken by averaging the results (at $0.1,0.5$ and $0.9 \mathrm{~V}$ vs. RHE) obtained after 8000 cycles from 0.6 to $1.0 \mathrm{~V}$ vs. RHE in $0.1 \mathrm{M} \mathrm{HClO}_{4}$ electrolyte. The figure has been adapted from our previous work on Gd/P(111) from ex situ XRD. ${ }^{[4]}$ 
Table 1. Tilt angles of the substrate, alloy, and overlayer phases. The caxis of the $\mathrm{Pt}(111)$ substrate, $\mathrm{Gd} / \mathrm{Pt}(111) \mathrm{RO}$ alloy, and the Pt overlayer were all tilted in the same direction from the surface normal. The amount of tilt was different for the three layers, and this resulted in an angle of the $c$-axis of the alloy and overlayer relative to the $\mathrm{Pt}(111)$ substrate.

\begin{tabular}{|lll|} 
& $\begin{array}{l}\text { Tilt vs. surface } \\
\text { normal }\left( \pm 0.1^{\circ}\right)\end{array}$ & $\begin{array}{l}\text { Tilt vs. Pt(111) } \\
\text { substrate }\end{array}$ \\
\hline $\mathrm{Pt}(111)$ substrate & $1.10^{\circ} \pm 0.02^{\circ}$ & - \\
$\mathrm{Gd} / \mathrm{Pt}(111)$ alloy & $1.280^{\circ} \pm 0.001^{\circ}$ & $0.18^{\circ} \pm 0.02^{\circ}$ \\
Pt overlayer & $1.60^{\circ} \pm 0.05^{\circ}$ & $0.50^{\circ} \pm 0.07^{\circ}$ \\
\hline
\end{tabular}

substrate. Due to both the alloy and the overlayer forming rather small domains, ${ }^{[42]}$ the tilt can either be a simple tilt of the hexagonal unit cell or a distortion of the unit cell with the $\alpha$-angle being slightly smaller than $90^{\circ}$. During this experiment we did not collect enough Bragg peaks to determine which of the two effects are present in the sample.

We also determined the strain and correlation length on the $\mathrm{Gd} / \mathrm{Pt}(111) R 30$ sample, in which both the overlayer and the alloy were rotated by $30^{\circ}$ compared to the $\mathrm{Pt}(111)$ substrate. ${ }^{[43]}$ Figure $5 a, b$ shows the strain as a function electrochemical treatment.

The strain was first measured directly after exposure to electrolyte at open circuit potential, at which point the overlayer had already formed (first point shown in Figure 5) a, b. The potential was then cycled from 0.0 to $1.0 \mathrm{~V}$ vs. RHE, after which the XRD was recorded while keeping the potential constant at $0.1 \mathrm{~V}, 0.5 \mathrm{~V}$, and $0.9 \mathrm{~V}$ vs. RHE. This process was repeated after cycling 0.00 to $1.20 \mathrm{~V}$ vs. RHE and 0.00 to $1.25 \mathrm{~V}$ vs. RHE. At every cycling step, we performed about 100 cycles at $20 \mathrm{mV} \mathrm{s}^{-1}$. Subsequently, the XRD pattern was recorded during cycling in the ranges: $0.0-1.3,0.0-1.4,0.0-1.5$, and $0.0-1.6 \mathrm{~V}$ vs. $\mathrm{RHE}$. The strain error bars represent the error from fitting, and the overall strain error is indicated by the $y$-axis in Figure 5. We quantified the correlation length as a function of the electrochemical treatment, carrying out a similar analysis to that shown for the $\mathrm{Gd} / \mathrm{Pt}(111) R 0$ sample. Figure $5 \mathrm{c}$, d shows the correlation length as a function of the electrochemical treatment for the $\mathrm{Gd} / \mathrm{Pt}(111) R 30$ sample.

It is important to mention that metallic Gd has a strong driving force to oxidise in aqueous electrolyte, and the equilibrium potential is about $-2.4 \mathrm{~V}$ vs. RHE in acidic conditions. ${ }^{[49]}$ This strong driving force is evidenced as the overlayer forms immediately upon exposure to the electrolyte at open circuit conditions (see Figure 5). However, the strong alloy formation energy and the thin Pt overlayer stabilise the catalyst against further dealloying. ${ }^{[37]}$ Interestingly, negligible changes in the $\mathrm{Pt}$ overlayer structure are observed at potentials below $1.0 \mathrm{~V}$ vs. $\mathrm{RHE}$, in agreement with the formation of a very stable overlayer on $\mathrm{Gd} / \mathrm{Pt}(111) R 30$. The measured in-plane compressive strain in that potential region is much lower to that measured on the non-rotated sample (presented in Figure 3), and is similar to the strain measured ex situ to a $\mathrm{Gd} / \mathrm{Pt}(111) R 30$ sample. ${ }^{[43]} \mathrm{How}$ ever, similar to the one measured on $\mathrm{Gd} / \mathrm{Pt}(111) R 0$, the out-ofplane strain is compressive on this sample, indicating the presence of Kagomé layer(s) on the overlayer.
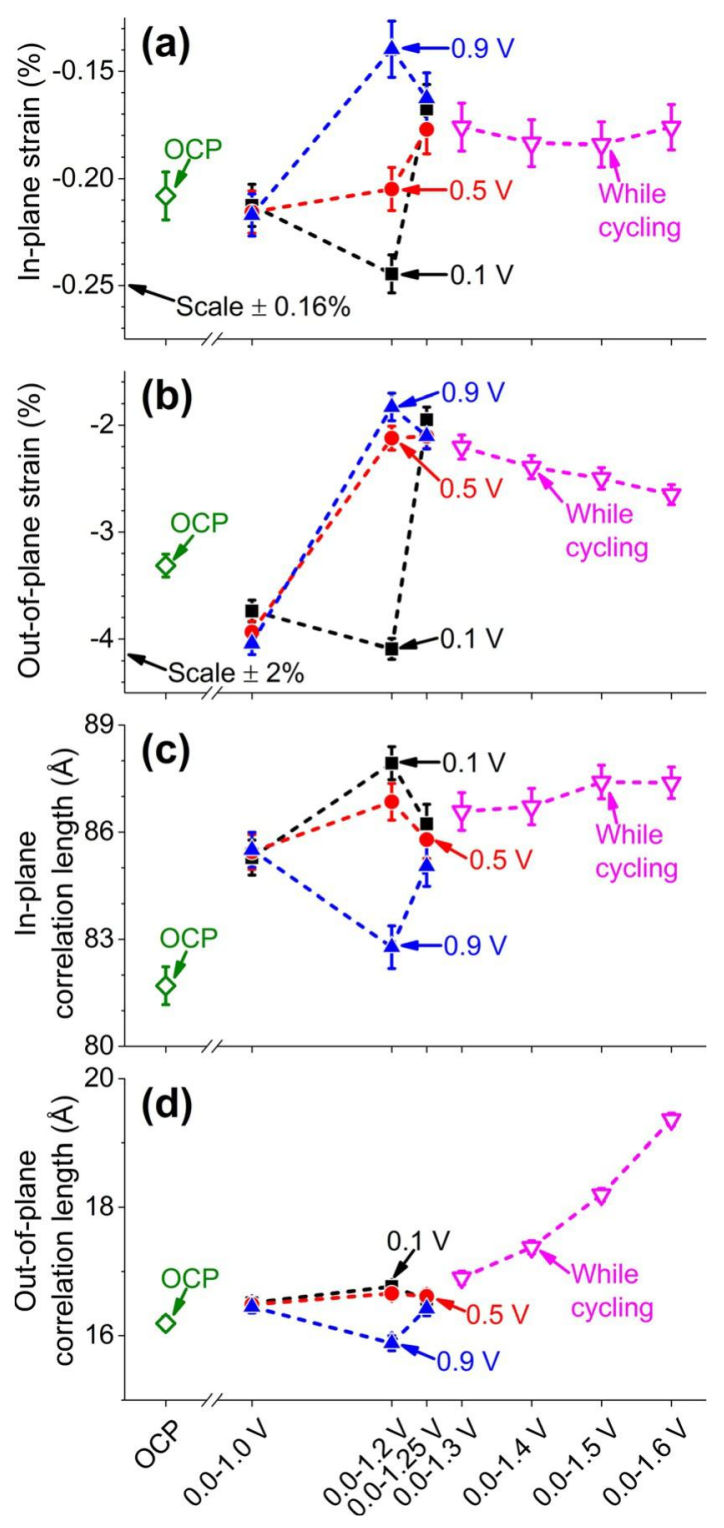

Figure 5. In-plane and out-of-plane components of the Pt overlayer strain (a, b) and correlation lengths $(c, d)$ as a function of electrochemical treatment for $\mathrm{Gd} / \mathrm{Pt}(111) R 30$. The overlayer was formed immediately upon exposure to electrolyte at open circuit potential (OCP), which is the first point shown. The electrode was then cycled 0.0 to $1.0 \mathrm{~V}$ vs. RHE, followed by XRD recording under constant potential of $0.1,0.5$ and $0.9 \mathrm{~V}$ vs. RHE. This process was repeated after cycling from 0.0 to $1.20 \mathrm{~V}$ vs. RHE and from 0.0 to $1.25 \mathrm{~V}$ vs. $\mathrm{RHE}$. Upon cycling up to higher potentials, the XRD pattern was recorded during the electrochemical cycling in the ranges: $0.0-1.3 \mathrm{~V}$ vs. RHE, $0.0-1.4 \mathrm{~V}$ vs. RHE, $0.0-1.5$ V vs. RHE, and 0.0-1.6 V vs. RHE.

Potentials above $1.2 \mathrm{~V}$ vs. RHE make drastic degradation of the overlayer, in terms of both thickness and strain, as the strain relaxes. Recent in situ STM studies by Koper and coworkers $^{[50]}$ and GI-XRD works by Magnussen and co-workers $^{[44,51]}$ have shown significant roughening of $\mathrm{Pt}(111)$ when cycling above $1.17 \mathrm{~V}$ vs. $\mathrm{RHE}$ in $0.1 \mathrm{M} \mathrm{HClO}_{4}$. In our experiments, a large spread is observed in both the strain and crystallite size depending on the potential at which the diffraction was obtained $(0.1,0.5$ or $0.9 \mathrm{~V}$ vs. RHE). Increasing the potential cycling limit up to $1.6 \mathrm{~V}$ vs. RHE revealed the formation of a re- 
laxed overlayer after cycling up to $1.25 \mathrm{~V}$ vs. RHE. In addition, both the in-plane compressive strain and the coherence lengths decrease while the out-of-plane components increase. Our observations are interpreted as effects of Pt oxidation and reduction, ${ }^{[44]}$ which may result in roughening, ${ }^{[44,50]}$ strain relaxation and thickening of the Pt overlayer. ${ }^{[33]}$

The two Gd/Pt(111) samples with a rotated (R30) and non-rotated $(R 0)$ overlayer display different amounts of compression with the non-rotated overlayer exhibiting the highest compression. The reasons for the formation of a rotated or non-rotated alloy phase are not understood, but controlling this is important as a higher compression to a certain extent will lead to a higher catalytic activity. ${ }^{[33]}$ The compression of the overlayer observed for the rotated overlayer (R30) is similar to the compression we measured ex situ on a similarly prepared $\mathrm{Gd}$ / $\mathrm{Pt}(111)$ crystal. ${ }^{[43]}$

As we described earlier, both $\mathrm{Gd} / \mathrm{Pt}(111) R 0$ and $\mathrm{Gd}$ / $\mathrm{Pt}(111) R 30$ show in-plane and out-of-plane compressive strain. This is unreasonable for a face-centered cubic (FCC) structure because this is already close-packed. However, the Gd/Pt(111) alloy structure contains Kagomé layers, ${ }^{[42]}$ and the presence of such layers inside the overlayer may support compression because these layers have vacancies. DFT calculations show that replacing the second or third atomic layer from the surface by a Kagomé layer, a simultaneous compression in-plane and outplane may occur. These data are shown in Figure 6; the model with Kagomé layers in the third and fourth atomic layers is consistent with our measurements. The structural changes caused by such a Kagomé layer only provides small changes to the XRD pattern compared to the FCC structure, as evidenced by simulations (see the Supporting Information, Figures S1 and S2), and these are not possible to detect with the current experimental setup.

After the in situ XRD measurements reported in Figure 3, we carried out further electrochemical characterisation on the $\mathrm{Gd} /$ $\mathrm{Pt}(111) R 0$ sample. This sample, contrary to the rotated $\mathrm{Gd}$ /

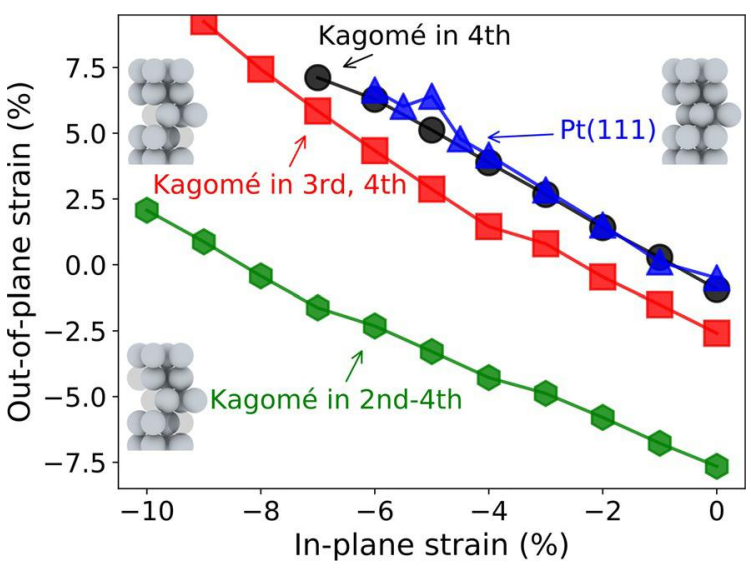

Figure 6. DFT calculations showing the relaxed out-of-plain strain between the outermost atomic layer and the third atomic layer (two interplanar distances) as a function of the constrained in-plane strain. Four structures are shown: Pt(111) (blue triangles) and Pt overlayers with a Kagomé layer in the second, third and fourth layers (green hexagons), third and fourth layers (red squares), or Kagomé in the fourth layer only (black circles).
Pt(111)R30 sample, had not been subjected to destructively high potentials because the potential was kept below $1.0 \mathrm{~V}$ vs. RHE all the time during the in situ XRD measurements on the $\mathrm{Gd} / \mathrm{Pt}(111) R 0$ sample. The electrochemical experiments on $\mathrm{Gd} /$ $\mathrm{Pt}(111) R 0$ were performed in a rotating ring-disk electrode (RRDE) three-electrode setup with a gas bubbler allowing the changing the gas saturated into the acidic electrolyte. ${ }^{[40]}$ For specific details on the electrochemical tests, see the Experimental Section. Given that the $\mathrm{Gd} / \mathrm{Pt}(111) R 0$ sample had undergone a total of about 8000 cycles between 0.6 and $1.0 \mathrm{~V}$ vs. RHE in the in situ GI-XRD setup, it was denoted Gd/Pt(111)R0*. Figure 7 shows the stable cyclic voltammograms (CVs) of Gd/ $\mathrm{Pt}(111) R 0^{*}$ in the range 0.05 to $1.00 \mathrm{~V}$ vs. RHE for both $\mathrm{Gd} /$ $\mathrm{Pt}(111) R 0^{*}$ and a pure $\mathrm{Pt}(111)$ single crystalline electrode.

CVs recorded at $50 \mathrm{mV} \mathrm{s}^{-1}$ in $\mathrm{N}_{2}$-saturated $0.1 \mathrm{M} \mathrm{HClO}_{4}$ after electrochemical conditioning of the electrode surface (see Figure S3, Supporting Information) are shown in Figure 7a. From the CVs, it is possible to observe the adsorption/desorption features from hydrogen ${ }^{[52]}$ and oxygen species such as hydroxyl. ${ }^{[17]}$ The features corresponding to both $\mathrm{H}$ adsorption (in the potential region from 0.05 to $0.45 \mathrm{~V}$ vs. RHE) and $\mathrm{OH}$ adsorption (from 0.55 to $1.00 \mathrm{~V}$ vs. RHE) are shown in Figure $7 \mathrm{a}$ as sketched areas. We evaluated the charge corresponding to the $\mathrm{H}$ adsorption region following the methodology described in our earlier works. ${ }^{[33,40,43]}$ Figure 7 a shows a considerable suppression of the $\mathrm{H}$ and $\mathrm{OH}$ adsorption regions for the $\mathrm{Gd} /$
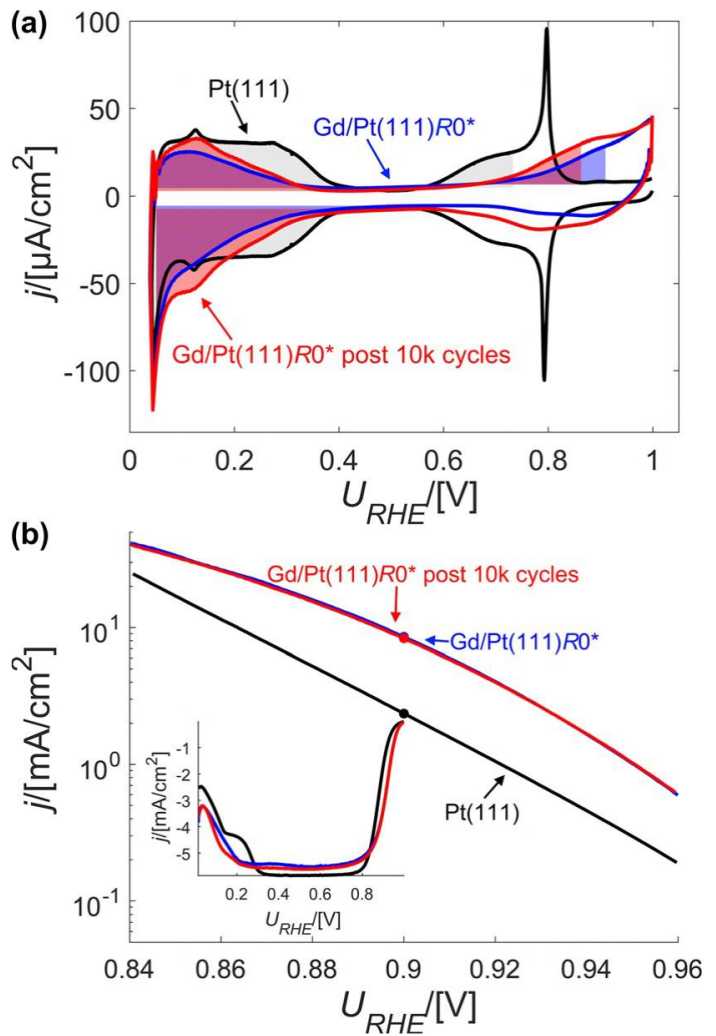

Figure 7. $\mathrm{CVs}$ on $\mathrm{Gd} / \mathrm{Pt}(111) \mathrm{RO}^{*}$ and $\mathrm{Pt}(111)$ in $0.1 \mathrm{M} \mathrm{HClO}_{4}$ at $50 \mathrm{mVs}^{1}$ and $23^{\circ} \mathrm{C}$. (a) Base $\mathrm{CV}$ in $\mathrm{N}_{2}$-saturated electrolyte taken at $400 \mathrm{rpm}$ before and after an accelerated stability test consisting of $10 \mathrm{k}$ cycles from 0.6 to $1.0 \mathrm{~V}$ vs. RHE. (b) Tafel plots (and anodic sweep of the cyclic voltammograms as insert) taken in $\mathrm{O}_{2}$-saturated electrolyte at $1600 \mathrm{rpm}$. 
$\mathrm{Pt}(111) R 0^{*}$ alloy as compared to $\mathrm{Pt}(111)$, suggesting extensive weakening of both $\mathrm{H}$ and $\mathrm{OH}$ binding energies to the surface. ${ }^{[3,43]}$ Given the thick pure Pt overlayer derived from Figures 3 and 4, together with the ex situ angle resolved X-ray photoelectron spectroscopy (AR-XPS) surface profile (Figure S5, Supporting Information), we can attribute this weakening to a compressive strain effect. ${ }^{[33]}$

The activity and stability of $\mathrm{Gd} / \mathrm{Pt}(111) R 0^{*}$ and $\mathrm{Pt}(111)$ towards the ORR was evaluated by means of cyclic voltammetry in an $\mathrm{O}_{2}$-saturated $0.1 \mathrm{M} \mathrm{HClO}_{4}$ electrolyte (Figure $7 \mathrm{~b}$ ). ${ }^{[32,33]}$ The current density was normalised by the geometric electrode area. ${ }^{[32,33,43]}$ The Tafel plots in Figure $7 \mathrm{~b}$ show the kinetic current density $\left(j_{k}\right)$, that is, the current density discounting effects from mass-transport limitations, as a function of the potential. Notably, Figure $7 \mathrm{~b}$ clearly shows a considerable enhancement of the activity for $\mathrm{Gd} / \mathrm{Pt}(111) R 0^{*}$ as compared to pure $\mathrm{Pt}(111)$. The specific activity of $\mathrm{Gd} / \mathrm{Pt}(111) R 0^{*}$ was $8.5 \mathrm{mAcm}^{-2}$ even after having carried out 8000 cycles between 0.6 and $1.0 \mathrm{~V}$ vs. RHE during the GI-XRD measurements at SSRL. These results indicate that the activity enhancement imposed from the formed strained Pt overlayer persisted after the in situ GI-XRD measurements. Indeed, Figure 3 showed that the in-plane strain in the $\mathrm{Gd} / \mathrm{Pt}(111) R 0$ sample hardly changes after the first 3000 cycles from 0.6 to $1.0 \mathrm{~V}$ vs. RHE. This suggests that from an activity per site perspective, a negligible loss would be expected by further cycling because the in situ GI-XRD data suggest a quite stable overlayer (strain) in this potential range. The combination of the GI-XRD data from Figure 3 and the experimental performance from Figure $7 \mathrm{~b}$ suggests that, once the highly active and stable compressed Pt overlayer is formed on the $\mathrm{Gd} / \mathrm{Pt}(111) R 0^{*}$ sample, it is maintained through cycling and various electrode transfers.

In addition to the ORR activity measurements, we further studied the stability of $\mathrm{Gd} / \mathrm{Pt}(111) R 0^{*}$ by performing an accelerated stability test ${ }^{[53]}$ consisting of 10000 continuous cycles between 0.6 and $1.0 \mathrm{~V}$ vs. RHE in $\mathrm{O}_{2}$-saturated $0.1 \mathrm{M} \mathrm{HClO}_{4}$ at $100 \mathrm{mV} \mathrm{s}^{-1}$ (see the Experimental Section). ${ }^{[32]}$ Interestingly, the Tafel plots for the ORR before (blue curve in Figure $7 \mathrm{~b}$ ) and after (red curve) the stability test show that the activity loss is negligible.

From Figure $7 \mathrm{a}$, we can evaluate the weakening in the in the $\mathrm{H}$ and $\mathrm{OH}$ binding by calculating the potential shift required to adsorb $1 / 6$ monolayers $(\mathrm{ML}$ ) of $\mathrm{OH}$ (that is $40 \mu \mathrm{Ccm}^{-2}$ assuming that $1 \mathrm{ML}$ corresponds to $240 \mu\left(\mathrm{cm}^{-2}\right),{ }^{[17,43,54]}$ as well as the $\mathrm{H}$ adsorption charge $\left(Q_{*_{H}}\right)^{[40]}$ for $\mathrm{Gd} / \mathrm{Pt}(111) R 0^{*}$ and $\mathrm{Pt}(111)$ (see sketched areas in Figure $7 \mathrm{a}$ ). Table 2 shows the kinetic current density at $0.9 \mathrm{~V}$ vs. RHE from Figure $7 \mathrm{~b}$, as well as the $\mathrm{H}$ and $\mathrm{OH}$ adsorption data for $\mathrm{Gd}$ / $\mathrm{Pt}(111)$. We have compared the CVs corresponding to the $\mathrm{Gd}$ / $\mathrm{Pt}(111) R 0^{*}$ sample before and after the accelerated stability test described above with that of pristine $\mathrm{Pt}(111)$. Thus, we gained insight into any initial electrocatalytic difference between $\mathrm{Pt}(111)$ and $\mathrm{Gd} / \mathrm{Pt}(111) R 0^{*}$, but also any structural changes arising from prolonged cycling of the $\mathrm{Gd} / \mathrm{Pt}(111) R 0^{*}$ electrode.

The results from Figure 7 and Table 2 reveal a considerable shift in the $\mathrm{OH}$ absorption potential for $\mathrm{Gd} / \mathrm{Pt}(111)^{[43]}$ relative to
Table 2. Specific activity (kinetic current density measured at $0.9 \mathrm{~V}$ vs. $\mathrm{RHE}), \mathrm{OH}$ potential shift, $\mathrm{H}$ adsorption total charge, and $\mathrm{H}$ adsorption charge relative to that of $\mathrm{Pt}(111)$ for $\mathrm{Gd} / \mathrm{Pt}(111)$ from the $\mathrm{CVs}$ in Figure 7.

\begin{tabular}{lllll|} 
Sample & $\begin{array}{l}j_{\mathrm{k}} \\
{\left[\mathrm{mAcm}{ }^{-2}\right]}\end{array}$ & $\begin{array}{l}\Delta U_{1 / 6{ }^{*} \mathrm{OH} \mathrm{ML}}[\mathrm{V}] \\
{\left[\begin{array}{l}Q_{* H} \\
{[\mu \mathrm{C}]}\end{array}\right.}\end{array}$ & $Q_{*_{H}} / Q_{*_{H}}^{P_{t}(111)}$ \\
\hline $\mathrm{Pt}(111)$ & $1.7 \pm 0.7$ & 0 & $176 \pm 12.7$ & 1.00 \\
$\mathrm{Gd} / \mathrm{Pt}(111) \mathrm{R} 30^{[33]}$ & $7.3 \pm 1.4$ & 0.104 & 124.8 & 0.71 \\
$\mathrm{Gd} / \mathrm{Pt}(111) \mathrm{RO}^{*}$ & 8.5 & 0.081 & 105.1 & 0.60 \\
$\mathrm{Gd} / \mathrm{Pt}(111) \mathrm{RO}^{*}$ & 8.3 & 0.034 & 140.4 & 0.80 \\
post 10000 cycles & & & & \\
\hline
\end{tabular}

$\mathrm{Pt}(111)$, indicating a significant weakening of the $\mathrm{OH}$ binding energy, ${ }^{[17,43]}$ in agreement with the ORR Sabatier volcano relationship. ${ }^{[17]}$ Moreover, Table 2 shows that the $\mathrm{H}$ adsorption region $^{[40,55]}$ is suppressed for $\mathrm{Gd} / \mathrm{Pt}(111) R 0^{*}$ relative to $\mathrm{Pt}(111)$, the extent of this suppression decreasing after the stability test. Notably, the $\mathrm{Gd} / \mathrm{Pt}(111) R 0^{*}$ system exhibits less than $2 \%$ difference in specific kinetic current density before and after the stability test. The combination of in situ GI-XRD and electrochemical measurements indicate that the strain relaxation correlates with stability. The electrochemical experiments unequivocally show enhanced activity relative to $\mathrm{Pt}(111)$ and great stability in lieu of the thick Pt overlayer. These results encourage the development of scalable methods to synthesise Pt-Gd nanoparticulate catalysts. ${ }^{[56]}$ Controlling the structure of these alloys will favour the formation of a stable Pt shell ${ }^{[38]}$ which may protect them towards degradation during prolonged cycling under fuel-cell reaction conditions in acidic media.

\section{Conclusions}

In this study, we have combined in situ surface sensitive XRD measurements, electrochemical experiments and theoretical calculations to study the formation and evolution of the active surface phase of well-defined $\mathrm{Gd} / \mathrm{Pt}(111)$ electrode surfaces. The electrodes were prepared by deposition of $\mathrm{Gd}$ on $\mathrm{Pt}(111)$ single crystals in UHV. ${ }^{[42]}$ Synchrotron-based in situ GI-XRD on $\mathrm{Gd} / \mathrm{Pt}(111)$ revealed the formation of a compressed Pt overlayer upon immersion into aqueous acidic electrolyte at open circuit potential.

The effect of prolonged cycling, between 0.0 and $1.0 \mathrm{~V}$ vs. $\mathrm{RHE}$, was investigated on a $\mathrm{Gd} / \mathrm{Pt}(111) R 0$ (non-rotated) sample. In situ XRD revealed a slight relaxation of the $\mathrm{Pt}$ overlayer when cycling increasingly into the region of relevance for ORR ( 0.6 to $1.0 \mathrm{~V}$ vs. RHE). After about 3000 cycles, the overlayer structure is stabilised and an approximately $0.8 \%$ compressively strained overlayer of about $8.3 \AA$ persisted after 8000 cycles, which is an indication of the formation of a very stable structure. The effect of cycling to increasingly higher potentials (up to $1.6 \mathrm{~V}$ vs. $\mathrm{RHE}$ ) was investigated on a Gd/Pt(111)R30 (rotated $30^{\circ}$ ) sample. We did not observe notable changes in the overlayer properties from open circuit potential to cycling up to $1.0 \mathrm{~V}$ vs. $\mathrm{RHE}$, indicating that once the overlayer is formed, it remains stable in this potential region. Increasing the potential cycling limits above $1.2 \mathrm{~V}$ vs. RHE resulted in: (i) coherence 
lengths and strain became dependent on the potential at which the XRD data was obtained; (ii) in-plane compressive strain and coherence lengths decreases, while the out-of-plane components increases, which we interpreted as Pt oxidation and $\mathrm{Gd}$ leaching, resulting in roughening, relaxation and thickening of the Pt overlayer.

\section{Experimental Section}

Preparation of $\mathrm{Gd} / \mathrm{Pt}(111)$ alloy and $\mathrm{Pt}(111)$ : The $\mathrm{Gd} / \mathrm{Pt}(111)$ alloy sample was prepared and characterised in a UHV chamber with a base pressure of $1 \times 10^{-10}$ torr. A full description of the UHV-setup can be found in the literature. ${ }^{[42,57]}$ The $\mathrm{Pt}(111)$ crystal was cleaned using sputtering with $1.2 \mathrm{kV}$ Ar ions and was subsequently characterised with X-ray photoelectron spectroscopy (XPS) to verify the cleanliness of the surface, and by low energy electron diffraction (LEED) and CO temperature programmed desorption (CO-TPD) $)^{[57]}$ to verify that the surface of the sample is single crystalline. To simulate the behaviour of a $\mathrm{Pt}_{5} \mathrm{Gd}$ single crystal, we prepared the sample by depositing $200 \AA$ of $\mathrm{Gd}$ on the surface of the Pt(111) crystal. We anticipate that by depositing a layer of this thickness, we prepared a surface that essentially behaves as a single crystal. The sample was kept at a temperature of $800^{\circ} \mathrm{C}$ during the $\mathrm{Gd}$ evaporation. This temperature is well above the mobility temperature of Gd in Pt and hence, by depositing at this temperature, we are forming both an alloy and a Pt overlayer that protect the Gd from oxidation. ${ }^{[42]}$ The sample was removed from the UHV chamber and transferred to SSRL for the in situ GI-XRD measurements. From the UHV characterisation, we concluded that we had created a $\mathrm{Pt}_{5} \mathrm{Gd}$ surface alloy terminated by a monolayer of $\mathrm{Pt}$.

The $\mathrm{Pt}(111)$ single-crystalline electrode used in the electrochemical experiments was prepared applying the methodology developed by Clavilier et al., consisting of flame-annealing the crystal and cooling in a controlled 1:1 $\mathrm{Ar} / \mathrm{H}_{2}$ (N5/N4.5) atmosphere. ${ }^{[58]}$

Synchrotron X-ray diffraction measurements: The diffraction measurements were performed at SSRL at beam line 7-2. This end station is equipped with a Huber six-circle diffractometer $(4 S+2 D)$ and a Pilatus $300 \mathrm{~K}$ area detector. The beam line has a Si(111) double-crystal monochromator, and we used a photon energy of $11 \mathrm{keV}$ to avoid fluorescence from the Pt by staying below the L3 absorption edge. When mounting a sample, the surface normal was aligned to the $\varphi$ rotation axis using a laser, and the angular accuracy was about $0.1^{\circ}$. For all the experiments, the incidence angle was set to $0.2^{\circ}$ to optimise surface sensitivity. Furthermore, the $\chi$ angle was fixed at $90^{\circ}$, giving a vertical $\varphi$-axis.

For convenience, we refer to the hexagonal unit cell for the $\mathrm{Pt}(111)$ surface, which has the lattice parameters: $a=b=2.775 \AA, c=$ $6.797 \AA, \alpha=\beta=90^{\circ}$, and $\gamma=120^{\circ}$. In this unit cell the $a$ - and $b$-axis are parallel to the surface, whereas the $c$-axis is perpendicular to the surface. The area detector was aligned such that the $(1,0,1)$, $(0,1,2)$, and $(1,0,4)$ diffraction spots from the $\mathrm{Pt}(111)$ substrate was visible upon correct rotation of the $\varphi$-axis. This also allows the recording of the diffraction from the overlayer once formed because this has an FCC-like structure. ${ }^{[43]}$ To record the entire diffraction peak, the $\varphi$-axis was rocked by $\pm 5^{\circ}$ during exposure.

Due to the curvature of the Ewald sphere, the reciprocal space image on the area detector is distorted. To correct for this, we used a powder pattern from a $\mathrm{LaB}_{6}$ crystal for calibration. The images were processed using MatLab programs developed by the authors to separate the in-plane and out-of-plane components of the scattering vector, $Q$. Furthermore, the intensity was also cor- rected for the Lorenz factor and the polarisation factor, assuming a $95 \%$ horizontal polarisation.

Electrochemical characterisation: The electrochemical measurements conducted during XRD at BL 7-2 were all obtained in a three-electrode hanging meniscus type cell developed by Friebel et al. ${ }^{[59]}$ The $\mathrm{Gd} / \mathrm{Pt}(111)$ single crystal working electrode was placed below the cell body, the counter electrode was a glassy carbon rod inside the cell body, and the reference electrode was a leak free $\mathrm{Ag} / \mathrm{AgCl}$ electrode (Innovative Instruments, Inc. LF-1.6, 3.4 M AgCl) inside the cell body as well (see Figure 1). The electrochemical procedure relied on the careful mounting of the $\mathrm{Gd} / \mathrm{Pt}(111)$ sample in the aggregate of Figure 1 and by careful injection of $\mathrm{HClO}_{4}$ (Merck, Suprapur $70 \%$ ) and positioning of the sample a hanging meniscus configuration could be obtained under open circuit conditions. $\mathrm{N}_{2}$ gas (N5) could be injected close to the hanging meniscus. By careful draping the meniscus using a thin Kapton film (Dupont) the $\mathrm{N}_{2}$ gas concentration could be elevated sufficiently for the hanging meniscus electrolyte to be considered $\mathrm{N}_{2}$-saturated. Furthermore, the hanging meniscus was maintained by slow but continuous injection of additional electrolyte.

After the synchrotron GI-XRD experiments, a Gd/Pt(111) sample which had not undergone destructively high potential cycling was sent to the Technical University of Denmark (DTU) for electrochemical characterisation. This was conducted in a three-electrode electrochemical cell, using a WMP2 potentiostat (Bio-Logic Instruments), following earlier procedures. ${ }^{[32,33,43,60]}$ The counter electrode was a $\mathrm{Pt}$ wire and the reference was a $\mathrm{Hg} \mid \mathrm{Hg}_{2} \mathrm{SO}_{4}$ (Schott), which was separated from the working electrode compartment using a ceramic frit.

Extensive electrochemical conditioning and cleaning of the sample surface (see the Supporting Information) was required after transferring the sample from SSRL to DTU. The sample was immersed in a rotating ring-disk electrode (RRDE) setup (Pine Instruments) under potential control at $0.1 \mathrm{~V}$ vs. RHE. After about 1200 cycles in $\mathrm{N}_{2}$-saturated (N5) electrolyte between 0.05 to $1.00 \mathrm{~V}$ vs. RHE at $200 \mathrm{mV} \mathrm{s}^{-1}$ and $400 \mathrm{rpm}$, stable CVs resembling those earlier obtained for $\mathrm{Gd} / \mathrm{Pt}(111)^{[43]}$ were observed. After obtaining a stable $\mathrm{CV}$, the sample was subjected to ORR evaluation in $\mathrm{O}_{2}$-saturated electrolyte at $1600 \mathrm{rpm}$ and $50 \mathrm{mV} \mathrm{s}^{-1}$. Following the ORR measurements, the electrolyte was saturated with $\mathrm{H}_{2}$ and the potential of the reference was checked against a RHE. All the potentials in the text are referred to the RHE and corrected for ohmic losses. Electrochemical impedance spectroscopy (EIS) was performed at $0.5 \mathrm{~V}$ vs. $\mathrm{RHE}$ in $\mathrm{N}_{2}$-staurated electrolyte to estimate the series resistance from the electrolyte and the contacts. ${ }^{[32,33]}$ The accelerated degradation test was done by carrying out 10000 cycles between 0.6 and $1.0 \mathrm{~V}$ vs. $\mathrm{RHE}$ in $\mathrm{O}_{2}$-saturated electrolyte at $100 \mathrm{mV} \mathrm{s}^{-1}$ without rotation. EIS, RHE and ORR were measured both after the stability test and after changing to fresh electrolyte.

Theoretical calculations: DFT calculations on the Pt overlayer models were conducted using the GPAW code ${ }^{[61]}$ and evaluation of exchange and correlation contributions were done using the RPBE functional. ${ }^{[62]}$ The single-electron wave functions were expanded in plane waves with an energy cut-off of $800 \mathrm{eV}$ and the Brillouin zone was sampled in an $8 \times 8 k$-point grid. The atomic structures were FCC like Pt(111) slabs with 6 atomic layers in $2 \times 2$ super cells, which were set up using the Atomic Simulation Environment package. ${ }^{[63]}$ The three bottom layers were constrained FCC(111) layers representing a bulk $\mathrm{Pt}(111)$ crystal structure, whereas the top three layers were allowed to relax, thus representing a relaxed surface with an in-plane strain. By varying the top three layers in combinations of FCC(111) Kagomé layers, the relaxed out-of-plane strain could be modelled while varying and constraining the lattice pa- 
rameter in the plane. Figure 6 shows the out-of-plane strain measured between the average atomic $z$-coordinate of the outermost layer and the average atomic $z$-coordinate of the third layer (two interplanar distances). The trends do not change significantly if the fourth layer was included in the measurement (three interplanar distances).

\section{Acknowledgements}

We gratefully acknowledge the Villum Foundation V-SUSTAIN grant 9455 to the Villum Center for the Science of Sustainable Fuels and Chemicals as well as the Strategic Research's project NACORR (12-133817) for funding this work. M.E.-E. acknowledges funding from the Danish Council for Independent Research under the Sapere Aude-Research Talent Program and the Villum Foundation under the VILLUM Young Investigator Programme. A.F.P. acknowledges the Danish Ministry for Higher Education and Science for an EliteForsk travel grant. K.D.J. gratefully acknowledges funding from KDfuelcell. We thank Apurva Mehta for his assistance with both synchrotron data acquisition and processing. The use of the Stanford Synchrotron Radiation Lightsource at SLAC National Accelerator Laboratory is supported by the U.S. Department of Energy, Office of Science, Office of Basic Energy Sciences under contract no. DEAC02-76SF00515.

\section{Conflict of interest}

The authors declare no conflict of interest.

Keywords: active phase - electrocatalysis - oxygen reduction reaction $\cdot$ platinum $\cdot$ X-ray diffraction

[1] S. Chu, Y. Cui, N. Liu, Nat. Mater. 2017, 16, 16-22.

[2] V. R. Stamenkovic, D. Strmcnik, P. P. Lopes, N. M. Markovic, Nat. Mater. 2017, 16, 57-69.

[3] W. T. Hong, M. Risch, K. A. Stoerzinger, A. Grimaud, J. Suntivich, Y. Shao Horn, Energy Environ. Sci. 2015, 8, 1404-1427.

[4] M. K. Debe, Nature 2012, 486, 43-51.

[5] A. Kongkanand, M. F. Mathias, J. Phys. Chem. Lett. 2016, 7, 1127-1137.

[6] I. E. L. Stephens, A. S. Bondarenko, U. Grønbjerg, J. Rossmeisl, I. Chorkendorff, Energy Environ. Sci. 2012, 5, 6744.

[7] M. Escudero-Escribano, K. D. Jensen, A. W. Jensen, Curr. Opin. Electrochem. 2018, DOI: https://doi.org/10.1016/j.coelec.2018.04.013.

[8] F. T. Wagner, B. Lakshmanan, M. F. Mathias, J. Phys. Chem. Lett. 2010, 1, 2204- 2219

[9] F. Calle-Vallejo, M. D. Pohl, D. Reinisch, D. Loffreda, P. Sautet, A. S. Bandarenka, Chem. Sci. 2017, 8, 2283-2289.

[10] J. Suntivich, K. J. May, H. A. Gasteiger, J. B. Goodenough, Y. Shao-Horn, Science 2011, 334, 1383-1385.

[11] J. K. Nørskov, J. Rossmeisl, A. Logadottir, L. Lindqvist, J. R. Kitchin, T. Bligaard, H. Jonsson, J. Phys. Chem. B 2004, 108, $17886-17892$.

[12] M. Busch, N. B. Halck, U. I. Kramm, S. Siahrostami, P. Krtil, J. Rossmeisl, Nano Energy 2016, 29, 126- 135.

[13] A. Kulkarni, S. Siahrostami, A. Patel, J. K. Nørskov, Chem. Rev. 2018, 118, $2302-2312$.

[14] J. R. Kitchin, J. K. Nørskov, M. A. Barteau, J. G. Chen, J. Chem. Phys. 2004, 120, $10240-10246$.

[15] P. Strasser, S. Koh, T. Anniyev, J. Greeley, K. More, C. Yu, Z. Liu, S. Kaya, D. Nordlund, H. Ogasawara, M. F. Toney, A. Nilsson, Nat. Chem. 2010, 2, $454-460$.
[16] M. Mavrikakis, B. Hammer, J. K. Nørskov, Phys. Rev. Lett. 1998, 81, $2819-$ 2822.

[17] I. E. L. Stephens, A. S. Bondarenko, F. J. Perez-Alonso, F. Calle-Vallejo, L. Bech, T. P. Johansson, A. K. Jepsen, R. Frydendal, B. P. Knudsen, J. Rossmeisl, I. Chorkendorff, J. Am. Chem. Soc. 2011, 133, 5485-5491.

[18] K. D. Jensen, J. Tymoczko, J. Rossmeisl, A. S. Bandarenka, I. Chorkendorff, M. Escudero-Escribano, I. E. L. Stephens, Angew. Chem. Int. Ed. 2018, 57, 2800-2805; Angew. Chem. 2018, 130, 2850-2855.

[19] M. Asano, R. Kawamura, R. Sasakawa, N. Todoroki, T. Wadayama, ACS Catal. 2016, 6, 5285-5289.

[20] H. A. Gasteiger, S. S. Kocha, B. Sompalli, F. T. Wagner, Appl. Catal. B 2005 56, 9-35.

[21] V. R. Stamenkovic, B. S. Mun, M. Arenz, K. J. J. Mayrhofer, C. A. Lucas, G. F. Wang, P. N. Ross, N. M. Markovic, Nat. Mater. 2007, 6, 241-247.

[22] T. Toda, H. Igarashi, H. Uchida, M. Watanabe, J. Electrochem. Soc. 1999, 146, 3750-3756.

[23] B. Han, C. E. Carlton, A. Kongkanand, R. S. Kukreja, B. R. C. Theobald, L. Gan, R. O'Malley, P. Strasser, F. T. Wagner, Y. Shao-Horn, Energy Environ. Sci. 2015, 8, 258-266.

[24] V. R. Stamenkovic, B. S. Mun, K. J. J. Mayrhofer, P. N. Ross, N. M. Markovic, J. Am. Chem. Soc. 2006, 128, 8813-8819.

[25] B. Fowler, C. A. Lucas, A. Omer, G. Wang, V. R. Stamenkovic, N. M. Markovic, Electrochim. Acta 2008, 53, 6076-6080.

[26] S. Mezzavilla, S. Cherevko, C. Baldizzone, E. Pizzutilo, G. Polymeros, K. J. J. Mayrhofer, ChemElectroChem 2016, 3, 1524-1536.

[27] M. Li, M. Li, Z. Zhao, T. Cheng, A. Fortunelli, C.-Y. Chen, R. Yu, Q. Zhang, L. Gu, B. V. Merinov, Z. Lin, E. Zhu, T. Yu, Q. Jia, J. Guo, L. Zhang, W. A Goddard III, Y. Huang, X. Duan, Science 2016, 354, 1414-1419.

[28] C. Chen, Y. Kang, Z. Huo, Z. Zhu, W. Huang, H. L. Xin, J. D. Snyder, D. Li, J. A. Herron, M. Mavrikakis, M. Chi, K. L. More, Y. Li, N. M. Markovic, G. A. Somorjai, P. Yang, V. R. Stamenkovic, Science 2014, 343, 1339-1343.

[29] I. E. L. Stephens, J. Rossmeisl, I. Chorkendorff, Science 2016, 354, 1378 1379.

[30] M. Inaba, A. W. Jensen, G. W. Sievers, M. Escudero-Escribano, A. Zana, M. Arenz, Energy Environ. Sci. 2018, 11, 988.

[31] J. Greeley, I. E. L. Stephens, A. S. Bondarenko, T. P. Johansson, H. A. Hansen, T. F. Jaramillo, J. Rossmeisl, I. Chorkendorff, J. K. Nørskov, Nat. Chem. 2009, 1, $552-556$.

[32] M. Escudero-Escribano, A. Verdaguer-Casadevall, P. Malacrida, U. Grønbjerg, B. P. Knudsen, A. K. Jepsen, J. Rossmeisl, I. E. L. Stephens, I. Chorkendorff, J. Am. Chem. Soc. 2012, 134, 16476-16479.

[33] M. Escudero-Escribano, P. Malacrida, M. H. Hansen, U. G. Vej-Hansen, A. Velázquez-Palenzuela, V. Tripkovic, J. Schiøtz, J. Rossmeisl, I. E. L. Stephens, I. Chorkendorff, Science 2016, 352, 73-76.

[34] U. G. Vej-Hansen, M. Escudero-Escribano, A. Velázquez-Palenzuela, P. Malacrida, J. Rossmeisl, I. E. L. Stephens, I. Chorkendorff, J. Schiøtz, Electrocatalysis 2017, 8, 594-604.

[35] P. Malacrida, M. Escudero-Escribano, A. Verdaguer-Casadevall, I. E. L. Stephens, I. Chorkendorff, J. Mater. Chem. A 2014, 2, 4234.

[36] L. Dubau, M. Lopez-Haro, L. Castanheira, J. Durst, M. Chatenet, P. BayleGuillemaud, L. Guétaz, N. Caqué, E. Rossinot, F. Maillard, Appl. Catal. B 2013, 142-143, $801-808$.

[37] U. G. Vej-Hansen, J. Rossmeis|, I. E. L. Stephens, J. Schiøtz, Phys. Chem. Chem. Phys. 2016, 18, 3302-3307.

[38] A. Velázquez-Palenzuela, F. Masini, A. F. Pedersen, M. Escudero-Escribano, D. Deiana, P. Malacrida, T. W. Hansen, D. Friebel, A. Nilsson, I. E. L. Stephens, I. Chorkendorff, J. Catal. 2015, 328, 297-307.

[39] P. Hernandez-Fernandez, F. Masini, D. N. McCarthy, C. E. Strebel, D. Friebel, D. Deiana, P. Malacrida, A. Nierhoff, A. Bodin, A. M. Wise, J. H. Nielsen, T. W. Hansen, A. Nilsson, I. E. L. Stephens, I. Chorkendorff, Nat. Chem. 2014, 6, 732-738.

[40] E. Zamburlini, K. D. Jensen, I. E. L. Stephens, I. Chorkendorff, M. Escudero-Escribano, Electrochim. Acta 2017, 247, 708-721.

[41] T. P. Johansson, E. T. Ulrikkeholm, P. Hernandez-Fernandez, M. EscuderoEscribano, P. Malacrida, I. E. L. Stephens, I. Chorkendorff, Phys. Chem. Chem. Phys. 2014, 16, 13718-13725.

[42] E. T. Ulrikkeholm, A. F. Pedersen, U. G. Vej-hansen, M. Escudero-escribano, I. E. L. Stephens, D. Friebel, A. Mehta, J. Schiøtz, R. K. Feidenhansl, A. Nilsson, I. Chorkendorff, Surf. Sci. 2016, 652, 114-122.

[43] A. F. Pedersen, E. T. Ulrikkeholm, M. Escudero-Escribano, T. P. Johansson, P. Malacrida, C. M. Pedersen, M. H. Hansen, K. D. Jensen, J. Rossmeisl, D. 
Friebel, A. Nilsson, I. Chorkendorff, I. E. L. Stephens, Nano Energy 2016, $29,249-260$.

[44] M. Ruge, J. Drnec, B. Rahn, F. Reikowski, D. A. Harrington, F. Carlà, R. Felici, J. Stettner, O. M. Magnussen, J. Am. Chem. Soc. 2017, 139, 4532 4539.

[45] H. You, D. J. Zurawski, Z. Nagy, R. M. Yonco, J. Chem. Phys. 1994, 100, $4699-4702$

[46] C. A. Lucas, M. Cormack, M. E. Gallagher, A. Brownrigg, P. Thompson, B. Fowler, Y. Gründer, J. Roy, V. R. Stamenkovic, N. M. Markovic, Faraday Discuss. 2009, 140, $41-58$

[47] Y. Gründer, C. A. Lucas, Nano Energy 2016, 29, 378-393.

[48] D. M. Smilgies, J. Appl. Crystallogr. 2009, 42, 1030-1034.

[49] N. Takeno, Natl. Inst. Adv. Ind. Sci. Technol. Tokyo 2005, 285.

[50] L. Jacobse, Y.-F. Huang, M. T. M. Koper, M. J. Rost, Nat. Mater. 2018, 17, $277-282$.

[51] J. Drnec, M. Ruge, F. Reikowski, B. Rahn, F. Carlà, R. Felici, J. Stettner, O. M. Magnussen, D. A. Harrington, Electrochim. Acta 2017, 224, $220-$ 227.

[52] H. E. Hoster, O. B. Alves, M. T. M. Koper, ChemPhysChem 2010, 11, 1518 1524.

[53] A. Ohma, K. Shinohara, A. liyama, T. Yoshida, A. Daimaru, ECS Trans. 2011, 41, 775- 784 .

[54] G. J. Edens, X. Gao, M. J. Weaver, N. M. Markovic, P. N. Ross, Surf. Sci. 1994, 302, L275-L282.

[55] M. J. T. C. van der Niet, N. Garcia-Araez, J. Hernández, J. M. Feliu, M. T. M. Koper, Catal. Today 2013, 202, $105-113$
[56] C. Roy, B. P. Knudsen, C. M. Pedersen, A. A. V. Palenzuela, L. H. Christensen, C. D. Damsgaard, I. E. L. Stephens, I. Chorkendorff, ACS Catal. 2018, 8, $2071-2080$.

[57] E. T. Ulrikkeholm, M. H. Hansen, J. Rossmeisl, I. Chorkendorff, Phys. Chem. Chem. Phys. 2016, 18, 29732-29739.

[58] J. Clavilier, R. Faure, G. Guinet, R. Durand, J. Electroanal. Chem. 1979 107, 205-209.

[59] D. Friebel, D. J. Miller, C. P. O'Grady, T. Anniyev, J. Bargar, U. Bergmann, H. Ogasawara, K. T. Wikfeldt, L. G. M. Pettersson, A. Nilsson, Phys. Chem. Chem. Phys. 2011, 13, 262-266.

[60] C. M. Pedersen, M. Escudero-Escribano, A. Velázquez-Palenzuela, L. H. Christensen, I. Chorkendorff, I. E. L. Stephens, Electrochim. Acta 2015, $179,647-657$.

[61] J. Mortensen, L. Hansen, K. Jacobsen, Phys. Rev. B 2005, 71, 35109.

[62] B. Hammer, L. Hansen, J. Nørskov, Phys. Rev. B 1999, 59, 7413-7421.

[63] A. Larsen, J. Mortensen, J. Blomqvist, I. Castelli, R. Christensen, M. Dulak, J. Friis, M. Groves, B. Hammer, C. Hargus, E. D. Hermes, P. C. Jennings, P. B. Jensen, J. Kermode, J. R. Kitchin, E. L. Kolsbjerg, J. Kubal, K. Kaasbjerg, S. Lysgaard, J. B. Maronsson, T. Maxson, T. Olsen, L. Pastewka, A Peterson, C. Rostgaard, J. Schiotz, O. Schutt, M. Strange, K. S. Thygesen, T. Vegge, L. Vilhelmsen, M. Walter, Z. Zeng, K. W. Jacobsen, J. Phys. Condens. Matter 2017, 29, 273002. 